This document is the accepted manuscript version of the following article:

Lämmlein, T. D., Messina, F., Wyrzykowski, M., Terrasi, G. P., \& Lura, P. (2019). Low clinker high performance concretes and their potential in CFRP-prestressed structural elements. Cement and Concrete composites, 100, 130-138.

https://doi .org/10.1016/j. cemconcomp. 2019.02.014

This manuscript version is made available under the CC-BY-NC-ND 4.0 1icense http://creativecommons.org/1icenses/by-nc-nd/4.0/

\title{
Low clinker high performance concretes and their potential in CFRP-
} prestressed structural elements

\author{
Tobias Dominik Lämmlein ${ }^{1,2}$, \\ Francesco Messina ${ }^{3,4}$, \\ Mateusz Wyrzykowski ${ }^{1}$, \\ Giovanni Pietro Terrasi, ${ }^{1,5}$, \\ Pietro Lura ${ }^{1,2}$ \\ 1 Empa, Swiss Federal Laboratories for Materials Science and Technology, Überlandstrasse 129, 8600 \\ Dübendorf, Switzerland; Tobias.Laemmlein@empa.ch \\ 2 Institute for Building Materials (IfB), ETH Zurich, 8092 Zurich, Switzerland \\ 3 Departement of Engineering, Pathenope University of Naples, \\ Centro Direzionale Isola C4, 80143 Naples, Italy \\ 4 National Interuniversity Consortium of Materials Science and Technology, \\ Via Giuseppe Giusti 9, 50121 Florence, Italy \\ 5 Institute for Infrastructure \& Environment, School of Engineering, University of Edinburgh, \\ EH9 3FB Edinburgh, UK; Giovanni.Terrasi@empa.ch
}

\begin{abstract}
Three novel low-clinker-high-performance concretes (LCHPC) with clinker replacement levels of 54, 58 and $70 \%$ were developed to substitute high-performance concrete (HPC) in carbon-fiber-reinforcedpolymer (CFRP) prestressed structural elements. The clinker substitution was achieved by a high amount of limestone filler and smaller amounts of metakaolin and silica fume. After 28 days, the LCHPCs reached high compressive strength values, between $77 \mathrm{MPa}$ and $88 \mathrm{MPa}$, and Young's moduli between $35 \mathrm{GPa}$ and $44 \mathrm{GPa}$. The LCHPCs showed self-compacting properties and low creep and shrinkage in comparison to a reference HPC.

A finite element analysis (FEA) of the internal stress development over time in CFRP-prestressed structural elements was performed, including creep and shrinkage. A higher prestress level was maintained in the LCHPCs compared to the reference concrete, thanks to their low shrinkage and creep. In contrast, the use of ultra-high-modulus CFRP prestressing tendons leads to increased pre-stress losses.
\end{abstract}

\section{Keywords}

Prestressed concrete

Low-clinker-high-performance-concrete

Concrete creep

Concrete shrinkage

CFRP

Finite element analysis 


\section{Introduction}

In the last two decades, sustainability-oriented design of building materials has received increasing attention. Due to the large amounts of concrete that are currently employed to build and maintain the infrastructure and the built environment, it becomes paramount to reduce the emissions that are in particular associated with Portland cement clinker production. The production of cement is currently responsible for about $5 \%$ of the worldwide anthropogenic $\mathrm{CO}_{2}$ emissions [1,2]. An effective and promising approach to reduce the environmental impact of concrete structures is the reduction of the clinker content by optimizing the mixtures through supplementary cementitious materials (SCM) that are characterized by lower $\mathrm{CO}_{2}$ emissions. Until a short while ago, the possible substitution levels of Portland cement with SCM were quite limited. Today, national and regional standards and guidelines (e.g., the recent SIA [3] guidelines in Switzerland or the EN-197 [4] in Europe) permit the use of concretes with significant amounts of cement replacement to allow the development of more sustainable concrete structures.

In Europe, the set of SCMs is generally given by the EN 197 [4] standard. In this framework, significant replacement levels of clinker are already possible. However, depending on the exposure classes, the required minimum cement content (MCC) of a mixture is defined by the standard EN 206-1 [5]. For example, in the case of XA3 and XS3 classes, the MCC can be as high as $360 \mathrm{~kg} / \mathrm{m}^{3}$. In this case, the code-based approach poses effective limits to the design of sustainable low-clinker concretes (LCC). In 2009, Wassermann et al. [6] suggested a reconsideration of the concept of MCC. The authors argued that this parameter was a heritage of traditional concrete technology, when workability was not tunable by means of high range water reducing admixtures (HRWRA). They presented results related to durability such as carbonation and chloride ingress, demonstrating that the MCC was not a dominant parameter and that the service life was not negatively impacted by decreasing the cement content. In addition, other studies dealing with the influence of the code-based approach on the concrete compositions can be found in the literature, focusing on several aspects such as durability $[7,8]$, mechanical properties [9] and structural design parameters [10].

Calcined clays as SCM have started to receive substantial attention only in the last few years, even if the first systematic studies on the application of these pozzolans in concrete date back to the 1980s. Murat [11] reported a study on the hydration of metakaolin obtained by heating a commercial poorlycrystalline and fine-grained kaolinite (97-98\% kaolinite) in a small fixed-bed electric furnace for six hours at about $730^{\circ} \mathrm{C}$. This sample was mixed with water and activated by means of lime. The main reaction products were hydrated gehlenite, $\mathrm{C}-\mathrm{S}-\mathrm{H}$ and small quantities of tetra calcium aluminate hydrate $\left(\mathrm{C}_{4} \mathrm{AH}_{13}\right.$ in cement chemistry notation). In subsequent studies [12-15], several dominant factors in calcined clays technology were discussed, such as the influence of raw material mineralogy, calcination technique and calcination conditions. The chemical and mineralogical properties of raw kaolin and the industrial processes for calcination are still the subject of research today. In [16], San Nicolas et al. investigated the properties of metakaolin obtained by means of flash calcination and compared them to those obtained by traditional rotary kiln calcination of the same kaolinite sources. The authors showed that flash calcination improved the rheological performance without affecting the chemical composition. The workability improvement is determined by the morphology of the flash-calcined metakaolin (FCMK), which contains a fraction of spherical particles, while the typical morphology of metakaolin particles from rotary kilns is rather flaky.

More recently, it has been shown that the combined use of limestone and calcined clays allows achieving higher degrees of clinker substitution and a marked improvement in mechanical properties and durability. In [17], 45\% Portland cement substitution (30\% metakaolin, 15\% limestone) resulted in better mechanical properties at 7 and 28 days than the pure Portland cement reference. The synergy between the two supplementary cementitious materials is explained by the fact that calcium carbonate reacts with alumina from the metakaolin, forming additional AFm phases and stabilizing ettringite [18].

SCM are often applied in high-performance concrete (HPC) [19]. This particular concrete type is characterized by dense packing of the aggregate, small maximum aggregate size, water-to-cement ratio $(\mathrm{w} / \mathrm{c})$ around $0.40-0.30$ or lower (essential to obtain low porosity and high strength) and often addition 
of fine fillers or supplementary cementitious materials (usually silica fume [20], more recently also metakaolin [21]). Self-compacting concrete is obtained by appropriate grading of aggregates, cement and fillers and addition of superplasticizer and optionally viscosity modifiers [22]. By combining the high strength of HPC with self-compacting properties [23, 24], highly-optimized, thin-walled concrete elements become possible. To improve the particle packing and increase the compressive strength, typically 10 to $20 \%$ by cement mass of silica fume is used in HPC (e.g. [25]). However, besides increasing strength and reducing diffusivity [26], the refinement of the pore structure and especially the pozzolanic reaction of silica fume results in an increase of the autogenous shrinkage of HPC [27].

In HPC, due to the low w/c, complete hydration of cement cannot be reached. Cement hydration stops both due to lack of free water and lack of free pore space for forming new hydration products [28]. As a consequence, a substantial amount of cement $(30-50 \%$, depending on the $\mathrm{w} / \mathrm{c}$ and on the amount and type of supplementary cementitious materials in the mixture) will remain unhydrated, ultimately wasting resources and energy invested in cement production [29]. By replacing the expensive particles of unhydrated cement with non-reactive fillers, cheaper and "greener" HPC can be produced. Bonavetti et al. [29] showed that in mixtures with $\mathrm{w} / \mathrm{c} 0.30$ and 0.34 , almost the same compressive strength was obtained with $10 \%$ limestone substitution. At $20 \%$ substitution, the compressive strength was similar in the first 3 days and lower afterwards.

The substantial amounts of cement used in HPC mixtures highlight the necessity of making efficient use of the material, which is directly related to the degree of hydration of the cement at the given waterto-binder-ratio (w/b). Bentz and Conway [30] theoretically demonstrated the possibility to substitute coarser cement particles with inert fillers, without changing the mechanical performance at moderate substitution levels of up to $15 \%$. These numerical results were successively confirmed in experiments with limestone filler $[29,31]$. Recently, similar considerations allowed to develop static equivalent systems to study hydration-related early-age properties, shrinkage and creep, by substituting parts of the cement with inert quartz filler [32-35].

Based on the previous considerations, it can be assumed that in general the production of low clinker high performance concretes (LCHPCS) should be possible and that these mixtures could contribute to reduce the $\mathrm{CO}_{2}$ emissions. The environmental impact of a structure using these LCHPC materials would be reduced additionally if the structure itself could be designed to fulfill only the structural (static and dynamic) requirements, while avoiding the durability regulations that would require a thick reinforcement cover, and hence a larger volume of concrete. An example for such a structure would be a CFRP-prestressed precast beam, façade or pole element $[36,37]$. This technology allows benefiting from the outstanding mechanical properties of concrete in compression, while the CFRP do not need thick concrete covers to guarantee passivation and hence avoid corrosion of the reinforcement. In this particular application, the performance of prestressed structural elements is dependent on prestress loss, which is mainly related to creep, shrinkage and elastic shortening of the concrete [38]. Hence it would be beneficial, in terms of efficiency, if the used concrete would have a high elastic modulus in combination with low creep and shrinkage. A recent study already showed that a CFRP-prestressed structure should be able to reduce the environmental impact by up to $28 \%$ in comparison to an equivalent steel-prestressed structure [39]. Due to the low clinker content in LCHPC, carbonation is expected to be accelerated $[40,41]$. However, this is again not expected to be a problem for the proposed application, as long as non-corrosive CFRP is used for prestressing.

Accordingly, the proposed combination of CFRP utilization, in terms of its mechanical design possibilities [42], and LCHPC in prestressed structural elements is expected to lead to lighter, more sustainable and finally more functional designs.

One main goal of this study is developing novel concrete recipes for structural applications with the mechanical performance of a HPC, but with significantly lower clinker contents. In addition, low shrinkage, low creep as well as a good bond between the CFRP prestressing tendon and the novel LCHPCs are essential to allow the application of these mixtures for manufacturing thin, prestressed structural elements. 
Consequently, this work intends to show the potential impact of LCHPCs and of different CFRP materials to the remaining prestress level in a structure and hence to set the basis for an efficient structural design of prestressed concrete elements that takes into account also the material properties and the volume changes of the concrete.

\section{Materials and methods}

Three new LCHPCs were developed, characterised mechanically and for their volume changes. Furthermore they were tested in bond pull-out tests with sand coated UHM CFRP tendons. The related materials, their characterization methods and the bond testing are described in this section.

\subsection{Materials}

Three LCHPCs (C2, C3 and C4) were designed to compete with an industrial reference (C1) in terms of their basic mechanical properties. The industrial reference itself was reproduced from a mixture used in the Swiss precast industry for prestressed concrete elements (see Section 1); this mixture was used recently also in [42].

In general, all mixtures (C1-C4) contained ordinary, rapid hardening Portland cement CEM I $52.5 \mathrm{R}$ (calculated modified Bogue composition by mass [43] $C_{3} S 52.6 \%, C_{2} S$ 19.4\%, $C_{3} A$ 5.8\%, $C_{4} A F 11.2 \%$ ), but in descending amounts. The specific surface of cement was equal to $5100 \mathrm{~cm}^{2} / \mathrm{g}$ and median particle diameter $d_{50}=10.3 \mu \mathrm{m}$ (laser diffraction). The fly ash used in the mixture $\mathrm{C} 1$ had Blaine fineness equal to $2370 \mathrm{~cm}^{2} / \mathrm{g}$. To compensate for the reduced cement content, the LCHPCs contained high volumes of limestone filler (sh_stone ash ${ }^{\circledR}$, sh minerals $\mathrm{GmbH}$; density $2700 \mathrm{~kg} / \mathrm{m}^{3}, 98.5 \%$ by mass of $\mathrm{CaCO}_{3}$, median particle size $d_{50}=6 \mu \mathrm{m}$ ). In addition, the mixtures named $C 2$ and $C 3$ contained also smaller amounts of calcined clay (flash-calcined metakaolin, Argeco), in the case of C3 in combination with silica fume (968$\mathrm{U}^{\circledast}$, Elkem), as pozzolanic material. In the last mixture, named $\mathrm{C} 4$, only silica fume was used in addition to the filler. The oxide composition and the density of the cement, fly-ash, metakaolin and silica-fume are reported in Table 1 . The sand $(0 / 4 \mathrm{~mm})$ and gravel $(4 / 8 \mathrm{~mm})$ quantity was kept constant in all mixtures considered (the volume fraction of the aggregates in the mixtures is approximately 0.60 , while the volume ratio of sand to gravel is approximately 0.44$)$. In comparison to $C 1(\mathrm{w} / \mathrm{b}=0.35)$, the water to binder ratio of $\mathrm{C} 2-\mathrm{C} 4(\mathrm{w} / \mathrm{b}=0.17-0.2)$ was lowered to a minimum that still allowed good workability, in order to counteract the expected lower strength of these material due to substitution of the cement. To reach self-compacting properties, the amount of superplasticizer (SP) (ViscoCrete2OHE, SIKA) had to be increased substantially in the mixtures with reduced cement content. Compared to the industrial reference (C1), the clinker reduction of the LCHPCs (C2-C4) reached values of $54 \%, 58 \%$ and $70 \%$, respectively. The mixture compositions are shown in Table 2, which includes the fresh concrete properties.

Table 1: Oxide composition for cement, fly-ash, metakaolin and silica fume

\begin{tabular}{|c|c|c|c|c|}
\hline & CEM I $52.5 \mathrm{R}$ & Fly-ash & Silica fume & Metakaolin \\
\hline $\mathrm{SiO}_{2}$ (mass \%) & 20.2 & 54.8 & 96.5 & 72.1 \\
\hline $\mathrm{Al}_{2} \mathrm{O}_{3}$ (mass \%) & 5.3 & 24.5 & 0.7 & 22.3 \\
\hline $\mathrm{Fe}_{2} \mathrm{O}_{3}$ (mass \%) & 3.3 & 8.5 & 0.3 & 2.2 \\
\hline $\mathrm{MnO}$ (mass \%) & 0.1 & 0.2 & - & - \\
\hline $\mathrm{TiO}_{2}$ (mass \%) & 0.3 & 1.0 & - & 1.1 \\
\hline $\mathrm{P}_{2} \mathrm{O}_{5}$ (mass \%) & 0.2 & 0.3 & 0.1 & - \\
\hline $\mathrm{CaO}$ (mass \%) & 62.3 & 1.9 & 0.4 & 0.7 \\
\hline $\mathrm{MgO}$ (mass \%) & 1.7 & 3.0 & - & - \\
\hline $\mathrm{K}_{2} \mathrm{O}$ (mass \%) & 0.9 & 3.2 & 0.9 & 0.2 \\
\hline $\mathrm{Na}_{2} \mathrm{O}$ (mass \%) & - & 0.2 & - & - \\
\hline $\mathrm{SO}_{3}$ (mass \%) & 3.8 & - & - & - \\
\hline L.O.I. (mass \%) & 1.3 & 2.2 & - & 1.1 \\
\hline Particle density $\left(\mathrm{kg} / \mathrm{m}^{3}\right)^{\mathrm{a}}$ & 3150 & 2130 & 2200 & 2200 \\
\hline
\end{tabular}


Table 2: Concrete composition and fresh concrete properties

\begin{tabular}{|c|c|c|c|c|}
\hline Materials v & $\mathrm{C} 1^{\mathrm{c}}$ & $\mathrm{C} 2$ & $\mathrm{C} 3$ & $\mathrm{C} 4$ \\
\hline Cement $\left(\mathrm{kg} / \mathrm{m}^{3}\right)$ & 443.0 & 204.0 & 186.1 & 134.3 \\
\hline Fly ash $\left(\mathrm{kg} / \mathrm{m}^{3}\right)$ & 120.0 & - & - & - \\
\hline Limestone & - & 412.7 & 372.1 & 511.7 \\
\hline Silica fume $\left(\mathrm{kg} / \mathrm{m}^{3}\right)$ & 20.0 & - & 93.0 & 67.2 \\
\hline Metakaolin $\left(\mathrm{kg} / \mathrm{m}^{3}\right)$ & - & 56.8 & 46.5 & - \\
\hline Aggregates $0 / 4\left(\mathrm{~kg} / \mathrm{m}^{3}\right)$ & 1107.0 & 1105.6 & 1100.0 & 1097.9 \\
\hline Aggregates $4 / 8\left(\mathrm{~kg} / \mathrm{m}^{3}\right)$ & 487.0 & 486.0 & 484.0 & 483.0 \\
\hline Water & 204.0 & 135.6 & 118.6 & 121.2 \\
\hline Superplasticizer $\left(\mathrm{kg} / \mathrm{m}^{3}\right)$ & 5.2 & 25.6 & 25.1 & 16.4 \\
\hline$w / b$ & 0.35 & 0.2 & 0.17 & 0.17 \\
\hline $\mathrm{w} / \mathrm{c}$ & 0.46 & 0.66 & 0.64 & 0.92 \\
\hline Clinker reduction (\%) & 0 & 54 & 58 & 70 \\
\hline Bulk density $\left(\mathrm{kg} / \mathrm{m}^{3}\right)^{a}$ & 2307 & 2388 & 2367 & $2368^{b}$ \\
\hline Air void content (vol\%) & 3.6 & 3.9 & 4.8 & $3.2^{\mathrm{b}}$ \\
\hline Concrete flow $(\mathrm{cm})$ & 72.5 & 69 & 58 & $57.5^{\mathrm{b}}$ \\
\hline
\end{tabular}

a after 3 days

${ }^{b}$ measured on one additionally mixed batch

csame recipe as in [42]

The final concrete compositions were mixed in a 75-I Eirich R08W mixer following the same mixing procedure for all four recipes. First, the dry components were tumbled for $60 \mathrm{~s}$, afterwards water was added and finally the concrete was mixed for $120 \mathrm{~s}$ until a uniform mixture with good flow properties was achieved. Directly after mixing, the fresh concrete properties were measured according to EN 12350 and the different specimens were cast. Consequently, the experimental program of each investigated concrete was based on only one concrete batch. The mechanical properties of the developed concrete recipes, e.g. compressive strength and compressive Young's modulus, can be found in Table 3 of the results section.

The unidirectional CFRP tendons used in the pull-out tests consisted of Mitsubishi DIALED ${ }^{\text {TM }}$ K13916 ultra high modulus (UHM) carbon fibers (Mitsubishi Rayon Co. Ltd., Japan) in combination with a Huntsman XB3515/AD5021 hot-melt epoxy system. The tendons were produced by Carbolink AG (Fehraltdorf, Switzerland) in a tape laying method at a fiber volume content of $67 \%$. To enhance the bond with the concrete, the cylindrical surface $(\mathrm{d}=5.3 \mathrm{~mm})$ of the prestressing tendon was coated with quartz sand particles with size of 63-500 $\mu \mathrm{m}$. It was shown earlier that sand in general [44, 45], and the chosen coating in particular, leads to an excellent and durable bond [42]. The described sand-coated UHM CFRP prestressing tendon was the same as already used in $[42,46]$ to study tendon pull-out and behavior of the tendons at high temperature, respectively. These tendons had a longitudinal elastic modulus of $509 \mathrm{GPa}$, a design tensile strength of $1400 \mathrm{MPa}$ and a fiber volume content of $66 \%$ [46].

\subsection{Experimental program}

The compressive strength of the concretes was tested on three $150 \times 150 \times 150 \mathrm{~mm}^{3}$ cubes after 3,7 and 28 days, following standard EN12390 [47]. Until testing, the samples were stored in a climatic room at $20^{\circ} \mathrm{C} \pm 0.3^{\circ} \mathrm{C}$ and $\mathrm{RH}>95 \%$.

Uniaxial creep in compression and shrinkage properties were measured on $120 \times 120 \times 360 \mathrm{~mm}^{3}$ prismatic specimens, generally following the standard SIA 262 at $20^{\circ} \mathrm{C} \pm 0.3^{\circ} \mathrm{C}$ and $70 \% \mathrm{RH} \pm 3 \% \mathrm{RH}$. However, the experimental procedure for creep testing was modified compared to the standard. Instead of loading the sample after 28 days with a stress corresponding to $30 \%$ of the material's compressive strength, the samples were loaded in a sequence of increasing compressive stress applied at 3,7 and 28 days after casting; at each loading step, the total stress was updated in order to correspond to $20 \%$ of the compressive strength at the time of loading. An overview of this specific loading procedure can be found in Figure 1. 


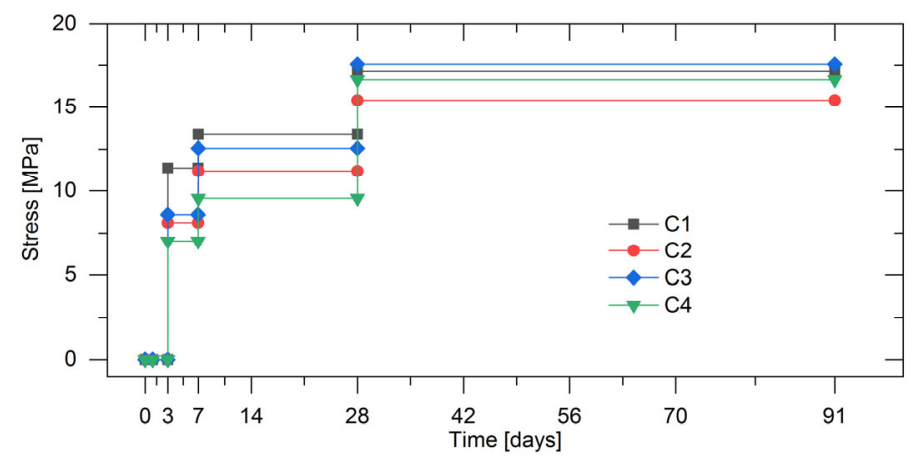

Figure 1: Scheme of the loading procedure - the stress applied on the samples at different ages is shown. The stress corresponded to $20 \%$ of the compressive strength (see Table 3 ) at the time of changing the load.

This procedure delivered valuable information about the creep behavior shortly after casting, which is of interest for the planned application to prestressed structural elements (pre-tensioning method for prefabrication). Furthermore, this allowed the calculation of the compressive Young's modulus by dividing the applied stress increase by the related strain increase for all considered concretes after 3,7 and 28 days, respectively. The change of length of each sample was measured, both for shrinkage and creep, by a Ditast- $250 \mathrm{~mm}$ high-precision distance meter (resolution $0.001 \mathrm{~mm}$, gauge length $250 \mathrm{~mm}$ ) on metal markers glued on two opposite sides of the prismatic specimens. All samples for creep and shrinkage measurements were cast from one batch per each concrete recipe and stored at a climate of $20^{\circ} \mathrm{C} \pm 0.3^{\circ} \mathrm{C}$ and $90 \% \mathrm{RH} \pm 3 \% \mathrm{RH}$ until demolding at $24 \mathrm{~h}$ after casting. The first measurement was done right after demolding. Next, the samples were exposed to drying at $20^{\circ} \mathrm{C} \pm 0.3^{\circ} \mathrm{C}$ and $70 \% \pm 3 \% \mathrm{RH}$. The total shrinkage measurements (performed on unloaded samples) were made at $1,3,7,14,28,35,42$, 56, 70 and $91 \mathrm{~d}$ after casting. Creep and shrinkage were measured each on two prisms for all four recipes. The measured total shrinkage values included shrinkage due to self-desiccation and due to drying. Creep was obtained by subtracting shrinkage strain (measured on unloaded samples) and the cumulative elastic strain from the total deformation measured on the two specimens under load.

In the pullout test program, five concrete prisms for each of the concrete recipes were cast. The prism geometry of $40 \times 40 \times 160 \mathrm{~mm}^{3}$ and the experimental setup was the same as used in an earlier study [42]. The sand-coated UHM-CFRP tendon, with a longitudinal stiffness of $509 \mathrm{GPa}$, was directed along the specimen's longitudinal axis. The bond area between tendon and concrete was limited by bond breakers to the inner $40 \mathrm{~mm}$ of the prism, allowing an unaffected load introduction. Detailed explanations and visualizations of the specimen's geometry and of the experimental setup can be found in [42]. The bond strength was obtained by pulling the whole specimen from one side of the CFRP tendon against a counter holder until failure and, at the same time, recording the applied force. The ultimate bond strength was calculated by dividing the measured maximum force by the initial bond area. The bond area was defined by calculating the CFRP tendons circumference based on its diameter after pullout failure. During loading, the tendon draw-in at the unloaded side of the specimen was recorded by a LVDT of type W2ATK HBM and the tendon draw-out at the loaded side of the test sample was monitored by two additional high-precision analogue sensors of type Baumer IPRM1219505/S14. The bond strength pull-out tests were performed for all four mixtures after 7 and after 28 days. Until testing, the samples were stored at $20^{\circ} \mathrm{C} \pm 0.3^{\circ} \mathrm{C}$ and $90 \% \mathrm{RH} \pm 3 \% \mathrm{RH}$.

\section{Results}

\subsection{Mechanical properties}

The main results presented here regard the LCHPC mixtures (C2-C4); more data on the reference mixture C1 can be found in [42]. 
Three days after casting the reference mixture $\mathrm{C} 1$ showed the highest compressive strength, followed by the systems $\mathrm{C} 3, \mathrm{C2}$, which used metakaolin as a cement replacement, and last $\mathrm{C} 4$ which only used silica fume. The increase in strength between 3 and 7 days is most evident for C3. At 28 days of age, all tested mixtures reached high strength. Even the weakest LCHPC mixture C2 reached an average value of $77.1 \mathrm{MPa}$, only $10 \%$ lower than $\mathrm{C} 1$. The results of the strength measurements are shown in Table 3 .

After 28 days, the compressive elastic Young's modulus ( $\left.E_{c 28 d}\right)$ of all mixtures with reduced clinker content exceeded that of the reference mixture. In the most extreme case, the modulus of C3 was $24 \%$ higher than the modulus of $\mathrm{C} 1$.

Table 3:

Compressive strength and E-modulus of the LCHPCs and their reference HPC.

\begin{tabular}{lcccccc}
\hline Recipe & $\mathrm{f}_{\mathrm{c} 3 \mathrm{~d}}(\mathrm{MPa})$ & $\mathrm{f}_{\mathrm{c7d}}(\mathrm{MPa})$ & $\mathrm{f}_{\mathrm{c} 28 \mathrm{~d}}(\mathrm{MPa})$ & $\mathrm{E}_{\mathrm{c} 3 \mathrm{~d}}(\mathrm{GPa})$ & $\mathrm{E}_{\mathrm{c7d}}(\mathrm{GPa})$ & $\mathrm{E}_{\mathrm{c} 28 \mathrm{~d}}(\mathrm{GPa})$ \\
\hline \hline $\mathrm{N}=$ & 3 & 3 & 3 & 2 & 2 & 2 \\
\hline \hline $\mathrm{C} 1$ & $56.9 \pm 0.2$ & $66.9 \pm 0.4$ & $85.7 \pm 1.1^{\text {(a) }}$ & $29.0 \pm 0.9$ & $29.4 \pm 1.2$ & $35.4 \pm 0.4$ \\
$\mathrm{C} 2$ & $40.6 \pm 0.1$ & $56.0 \pm 0.7$ & $77.1 \pm 0.7$ & $27.9 \pm 0.1$ & $30.3 \pm 1.3$ & $35.7 \pm 0.0$ \\
$\mathrm{C} 3$ & $43.0 \pm 0.4$ & $62.8 \pm 0.4$ & $87.8 \pm 1.1$ & $29.5 \pm 0.5$ & $33.6 \pm 0.7$ & $44.0 \pm 1.5$ \\
$\mathrm{C} 4$ & $35.1 \pm 0.2$ & $47.8 \pm 0.1$ & $83.3 \pm 1.0$ & $26.8 \pm 0.2$ & $36.4 \pm 0.9$ & $38.8 \pm 0.6$ \\
\hline
\end{tabular}

\subsection{Shrinkage and Creep}

The industry-based reference mixture $\mathrm{C} 1$ showed higher shrinkage than any of the tested cementsubstituted mixtures (C2-C4). After 91 days, the measured values covered the range from $0.38 \%$ \% (C1) to $0.17 \%$ (C4).

The shrinkage rate for $\mathrm{C} 1$ was the highest during the first 28 days. Afterwards, the shrinkage rate of all mixtures was comparable (Figure 2, left).

The LCHPC mixtures (C2-C4) also showed much less overall creep. After 91 days, the mixtures C2, C3 and $C 4$ reached creep levels of 59, 48 and $67 \%$ of $C 1$, respectively (Figure 2, right). To appreciate the creep reduction, it must be taken into account that $71 \%$ of the load of C1 was imposed on C2 at $3 \mathrm{~d}$, $84 \%$ at 7 days and $90 \%$ at 28 days. For C3, these figures are $76 \%$ at $3 d, 94 \%$ at 7 days and $102 \%$ at 28 days. For $\mathrm{C} 4,62 \%$ at $3 d, 71 \%$ at 7 days and $97 \%$ at 28 days, see Figure 1 . Despite lower loads (especially at early ages), the overall creep reduction is still evident (in other words, the reduction of creep in the LCHPC mixtures is larger than the ratio of loads between the LCHPC and C1), in particular for C3.
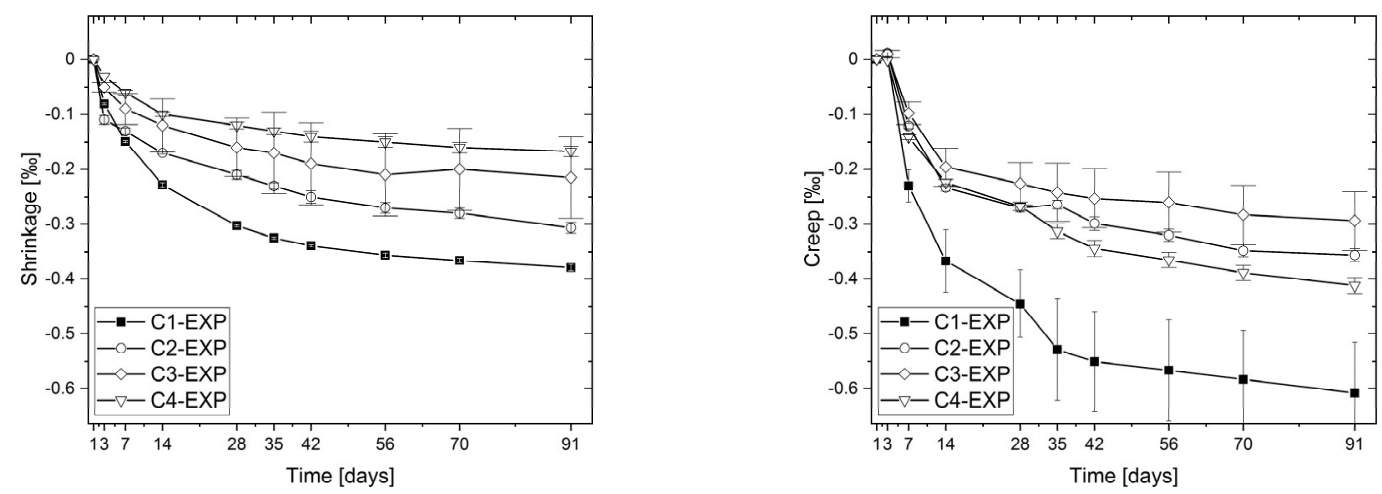

Figure 2: Shrinkage (left) and creep (right). In creep measurements, the load was increased to correspond to $20 \%$ of compressive strength at 3, 7 and $28 \mathrm{~d}$. C1 represents an industrial selfcompacting HPC as it is currently used in the Swiss precast industry. C2-C4 correspond to the newlydeveloped LCHPCs. 


\subsection{Bond of reinforcement in LCHPC}

The LCHPC mixtures showed bond strength values to sand-coated UHM-CFRP pre-stressing tendons similar to bond strength with conventional HPC reported in previous work [42]. Already after 7 days, the maximum bond strength for $\mathrm{C} 2-\mathrm{C} 4$ was in the range 17-21 MPa, not significantly different from $\mathrm{C} 1$.

As for the reference recipe $\mathrm{C} 1$, the tendon draw-in and-out was found to be linear approximately up to $75 \%$ of the maximum bond strength. At the loaded end, the draw-out rate of the tendon reached values between 11.1 and $12.5[\mu \mathrm{m} / \mathrm{MPa}]$, while at the unloaded end the tendons draw-in rate reached values between 3.4 and $4.3[\mu \mathrm{m} / \mathrm{MPa}$ ]. Afterwards, the tendon draw-in rate increased significantly until a sudden failure occurred. The failure occurred for all LCHPC samples in the same sudden manner of tendon slip-out failure and was comparable to the failure behaviour found for C1 in [42]. In particular the tendon slip-out failure could be proved to be a shear failure occurring between the CFRP tendon's surface and the sand coating layer. It is noticed that the scatter in bond strength is large but typical for such kind of pull out tests; see e.g. [48].

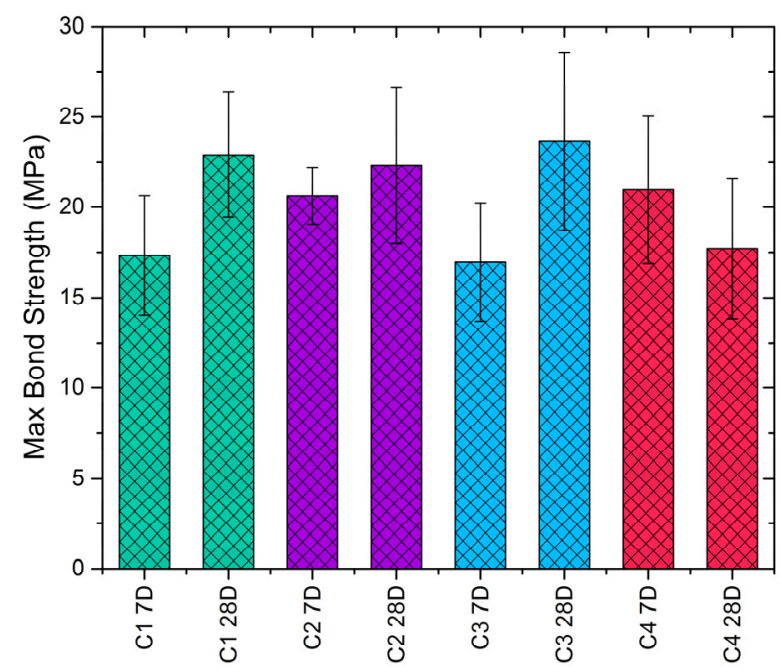

Figure 3: Bond performance of UHM-CFRP to LCHPC (C2-C4) and the reference concrete $\mathrm{C} 1$; data of C1 taken from [42].

\section{Discussion}

\subsection{Mechanical properties and volume changes of LCHPC}

The newly-developed LCHPCs reached high levels in their $28 \mathrm{~d}$ compressive strength and were comparable to the selected industrial reference. The cement reduction in the LCHPCs was compensated by a substantial decrease of the $\mathrm{w} / \mathrm{b}$ and corresponding low initial porosity and an increase in the solid fraction, which resulted in comparable or even higher elastic modulus already at early ages (Table 3). The LCHPCs generally showed a slower strength and slightly slower elastic modulus development in comparison to $\mathrm{C} 1$ (Table 3). This was mostly caused by the high amount of superplasticiser (see Table 2), that delayed setting and hardening [49]. While the reference $C 1$ contained $5.2 \mathrm{~kg} / \mathrm{m}^{3}$ of superplasticizer, C2 and C3 had about 5 times this amount and C4 3 times.

As expected (see e.g., [50]), the elastic modulus development was faster than the concrete strength development for all investigated mixtures and this was much more pronounced for the LCHPCs, see Table 4. A possible explanation is that the elastic modulus depends on the establishment of a percolated solids network through the microstructure [51], while the strength is known to be governed by the size of the largest defects present in the material. Cement hydration products connect quickly the solids (unhydrated cement and aggregates), while filling of the pores is a slower mechanism [51]. 
Table 4:

Development of compressive strength and elastic modulus in compression over time in respect to their 28d properties (100\%)

\begin{tabular}{lcccccccc}
\hline Time & $\mathrm{C} 1 \mathrm{f}_{\mathrm{c}}[\%]$ & $\mathrm{C} 1 \mathrm{E}[\%]$ & $\mathrm{C} 2 \mathrm{f}_{\mathrm{c}}[\%]$ & $\mathrm{C} 2 \mathrm{E}[\%]$ & $\mathrm{C} 3 \mathrm{f}_{\mathrm{c}}[\%]$ & $\mathrm{C} 3 \mathrm{E}[\%]$ & $\mathrm{C} 4 \mathrm{f}_{\mathrm{c}}[\%]$ & C4 E [\%] \\
\hline \hline 3d & 66 & 82 & 53 & 78 & 49 & 67 & 42 & 69 \\
$7 \mathrm{~d}$ & 78 & 83 & 73 & 82 & 71 & 76 & 57 & 94 \\
\hline
\end{tabular}

In bond tests between sand-coated UHM-CFRP tendons and LCHPCs, the results (i.e. maximum bond strength, tendon draw-in and mode of failure) were practically independent of the concrete mixture. The only detected bond-failure behavior for sand-coated UHM-CFRP tendons in LCHPCs was a slip-out failure as described previously for $\mathrm{C} 1$ [42]. Hence it can be assumed that, as for C1, also for LCHPCs C2C4 the failure mechanism is mainly related to the applied sand coating on the prestressing tendon. This is proposed to be valid at least for LCHPCs that reach strength and stiffness levels comparable to those of standard HPCs.

Creep was successfully reduced in the new LCHPCs, most likely due to $\mathrm{C}-\mathrm{S}-\mathrm{H}$ (resulting from hydration of cement) with elastic fillers. In fact, C-S-H is supposed to be the major phase experiencing viscoelastic behaviour among different phases in hydrated cement paste [52, 53]. On the other hand, the LCHPCs mixtures contain high volume of fillers that should be intrinsically elastic. Furthermore, the higher solids fraction and lower porosity of the LCHPC mixtures should further correspond to lower creep [54]. Examining closely the creep curves in Figure 2-right, a slight decrease in creep could be observed for the mixture $\mathrm{C} 2$ between $28 \mathrm{~d}$ and $35 \mathrm{~d}$. Considering that these values are based on the total deformation of only two tested specimens and that creep was calculated by subtracting the shrinkage of two additional shrinkage specimens, this drop can be explained mainly by natural variation between specimens.

The lower total shrinkage of the LCHPCs (C2-C4) compared with the reference $\mathrm{C} 1$ can be explained on one hand by the higher solid fraction (resulting in higher bulk modulus) [55]. The content of inert material by volume (aggregates and limestone filler, disregarding the limited reactivity of the limestone) is: $60.2 \%$ for C1 (65.8\% if we consider also fly ash as non-reactive), $75.3 \%$ for $\mathrm{C} 2,73.6 \%$ for $\mathrm{C} 3$ and $78.6 \%$ for C4. On the other hand, the lower shrinkage of the LCHPCs can be also explained by their lower C-S$\mathrm{H}$ content, since shrinkage can be considered as the viscoelastic response to the internal pore pressure $[56,57]$. If we assume that only the cement reacts in all mixtures (fly ash, metakaolin and silica fume are not expected to react completely), a simplified calculation based on Powers' model [28] yields an amount of hydration products by volume of concrete of $21.4 \%$ for $\mathrm{C} 1,9.8 \%$ for $\mathrm{C} 2,8.9 \%$ for $\mathrm{C} 3$ and $6.5 \%$ for $\mathrm{C} 4$. This is in any case an underestimation because part of the SCMs will also react. In any case, the differences between $\mathrm{C} 1$ and the LCHPC mixtures will remain large.

In addition, the autogenous shrinkage is reduced in the LCHPCs because, while the $\mathrm{w} / \mathrm{b}$ (considering limestone filler) is lower, the actual $\mathrm{w} / \mathrm{c}$ of these mixtures is higher than in the reference (see Table 1) and less self-desiccation occurs $[58,59]$. A low $\mathrm{w} / \mathrm{b}$ also results in a limited drying front penetration (due to lower porosity, permeability and diffusivity) and thereby in reduced rate of drying shrinkage [60]. It is noticed that the shrinkage reductions observed in the LCHPC mixtures depend on the mixture compositions that were used and on the reference $\mathrm{C} 1$. When substituting high amounts of cement with $\mathrm{SCMs}$, the creep and shrinkage reduction is expected to vary both with $\mathrm{w} / \mathrm{c}$ and with paste content.

\subsection{Effects of LCHPCs in CFRP-prestressed structures}

The new LCHPCs fulfilled the requested properties in terms of strength, stiffness, bond to sand-coated CFRP tendons and workability for their proposed application to prestressed structures. In a pre-stressed structure, it is important to know how much prestress is transferred and how the prestress changes over time. The main causes of prestress losses in prestressed concrete elements are elastic shortening, shrinkage and creep of concrete. Hence, the novel LCHPC recipes developed in this study, especially in combination with UHM-CFRP prestressing tendons, may significantly influence the prestress level that is maintained in the long term in such elements. It can be anticipated that the mechanical performance during the whole service life of a structural element manufactured according to this method might strongly depend on the chosen material combination. 
An Abaqus FEA model, including concrete creep and shrinkage, was used to estimate the losses corresponding to the mentioned three main contributors. Generally, the measured drying shrinkage of a concrete specimen can be considered to be the combined response of higher skin shrinkage and lower core shrinkage [61]. Upon drying, an internal RH and water saturation gradient is established in the specimen. These gradients induce higher shrinkage close to the surface (skin concrete) and lower shrinkage in the core of the specimen. Differential shrinkage results in self-induced stresses (the skin is in tension and the core is compressed) and the global shrinkage of the specimen at any time during drying is between that of the skin and that of the core. The shrinkage evolution depends further on the specimen's geometry, in particular on the surface to volume ratio. It is also known that the creep behavior is also strongly coupled with drying, see e.g. Pickett's effect [62]. For simplification and because the modelling of this complex behavior is not the focus of the present study, the implemented FEA model used the same geometry of $120 \times 120 \times 360 \mathrm{~mm}^{3}$ for the prestress-loss model beam geometry as used in the experimental creep and shrinkage testing. In this special case, the experimental results can be directly used as input for creep and shrinkage of the concrete in the model, at the cost of disregarding the shrinkage gradients within the specimens. It is noticed that while the shrinkage gradient may have initially some effect on the prestress losses, it is expected to show less influence as it becomes less steep with the progress of drying. In the case of specimens of relatively small cross section as examined here, the prestress loss of the tendon is expected to reflect mostly the global shrinkage/creep of the concrete specimen.

While the FEA model presented in the following has by necessity a number of simplifications, it is essential to quantify the effects of UHM-CFRP tendons and LCHPCs on the prestress losses. In particular, one may expect to obtain lower prestress losses as a result of the lower creep and shrinkage of LCHPCs. On the contrary, the high stiffness of UHM-CFRP tendons is expected to result in higher prestress losses than for conventional tendons. However, based on the mechanical properties of concrete and tendons and on the volume changes of the tendons, without an FEA model it is hardly possible to quantify the impact of each of the different phenomena on the prestress losses.

To apply the prestress on the chosen geometry, a total of four prestressing tendons ( $d=5.3 \mathrm{~mm}$ ) were placed symmetrically, as beam elements (Type B37), at one third of the sample's height and width along its longitudinal axes. A prestress could be applied to the tendons by a PREDEFINED FIELD of TYPE=STRESS and released after three days. The surrounding concrete was modelled using linear brick elements with reduced integration and hourglass control (Type C3D8R). As a simplification the tendons were superimposed on the concrete and a perfect bond between the tendon and the concrete was assumed. This restricts the validity of the prestress loss calculation on a fully prestressed and un-cracked beam section. Further this simplification does not include a detailed bond-slip modelling approach which would be needed for further analysis of ultimate loading in prestressed members. In the respective case of investigating prestress losses without additional structural loads, bond slip can be assumed to be irrelevant and hence it was neglected during this modelling. The sample beam was only restricted by a symmetry boundary condition at one side. This choice of boundary condition allows visualizing the prestress drop at the free end of the specimen and also shows the stress situation in the fully prestressed section. A visual overview of the FEA model is given in Figure 4. 


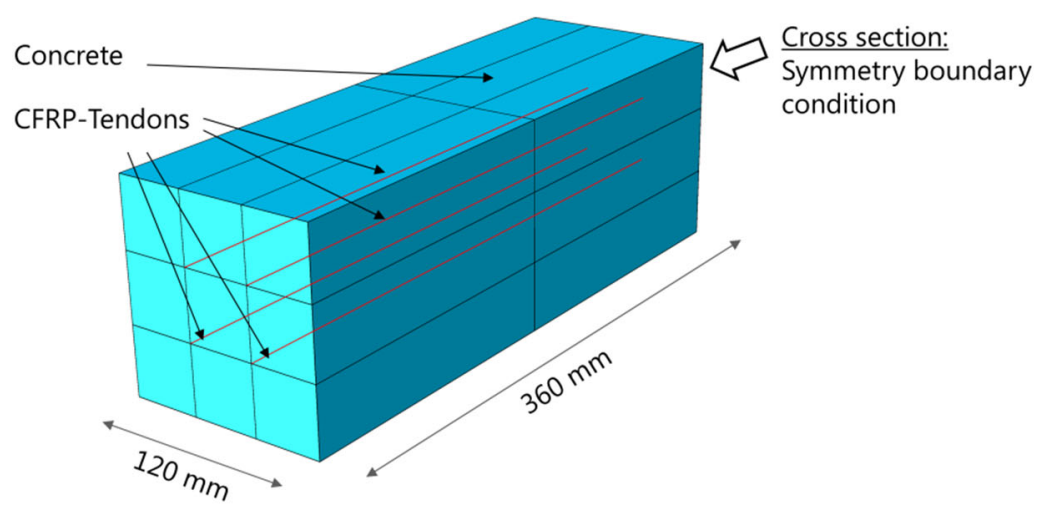

Figure 4: Overview of the Abaqus FEA-model. The concrete prism is visualized in blue, the four prestressing tendons in red colour.

The elastic behavior of the CFRP tendon and the concrete was modelled using ${ }^{\star} E L A S T I C$ of $T Y P E=E N G I N E E R I N G$ CONSTANTS and ${ }^{*} E L A S T I C$ of TYPE=ISOTROPIC respectively. In addition, Abaqus allows defining a temperature-dependent elastic modulus. This approach was used to model the time dependence of the four concrete mixtures by linking their tested $3 \mathrm{~d}, 7 \mathrm{~d}, 28 \mathrm{~d}$ elastic modulus to the corresponding fictitious temperatures used for shrinkage modelling (see details below). To assess the full range of CFRP tendon materials influence on prestress, an industry standard (UTS $E_{11}=138 \mathrm{GPa}$ ) tendon and a new ultra-high modulus tendon (UHM-K13916 $E_{11}=509 \mathrm{GPa}$ ) were chosen; their mechanical properties were taken from [42]. Based on [63], stress relaxation of the tendons is expected to reduce the prestress by less than $1.4 \%$ in the case of UTS-CFRP and around $1.1 \%$ for UHM-CFRP tendons. This loss was not considered in the FEA and would show no significant effect on the results presented in Figure 6, Figure 7 and Figure 8.

Shrinkage was modelled by a thermal expansion coefficient analogy after [64]. In Abaqus 6.14, the shrinkage was implemented by the ${ }^{*} E X P A N S I O N$ function in combination with a predefined fictitious temperature field. The applied temperature was homogeneous throughout the complete model at each calculated time point but changed its absolute value over time to simulate the shrinkage. The final results of shrinkage modelling were evaluated and compared to the experiments. As expected, due to the strict numerical fit, the shrinkage behavior was found for all four mixtures to be very well represented by the applied model (see Figure 5A).

The creep of concrete was modelled in Abaqus using *VISCOELASTIC. In principle, this modelling approach can be expressed by a parallel arrangement of several Maxwell elements and a spring element. In this case a Prony series of the bulk relaxation modulus $k_{R}(t)$ and the shear relaxation modulus $g_{R}(t)$ describes the viscoelastic material behavior. For modelling the creep behaviour using creep test data, Abaqus requires the input of the normalized shear compliance. This shear compliance can be calculated by dividing the actual shear stress by the constant shear stress applied in shear creep tests [65].

To represent the creep behavior of all four recipes, the experimentally-gained uniaxial creep data was assumed as shear creep data in Abaqus and normalized. To provide support values in the area of low experimental data coverage, the normalized creep data was fitted to a logarithmical curve and finally added into Abaqus for material fitting. In addition, Abaqus allows defining the long term normalized shear compliance, which was set to best represent the creep curves in the long term. This procedure was applied to all four recipes and added into the FEA based on the results of the creep test program. In particular the creep load applied in the previous experiments after 3 days, 7 days and 28 days respectively was used when implementing the creep model in Abaqus. The results of this fit are summarized in Figure 5 B. The load variation over time was not further considered during the prestress loss assessment in the FEA. 


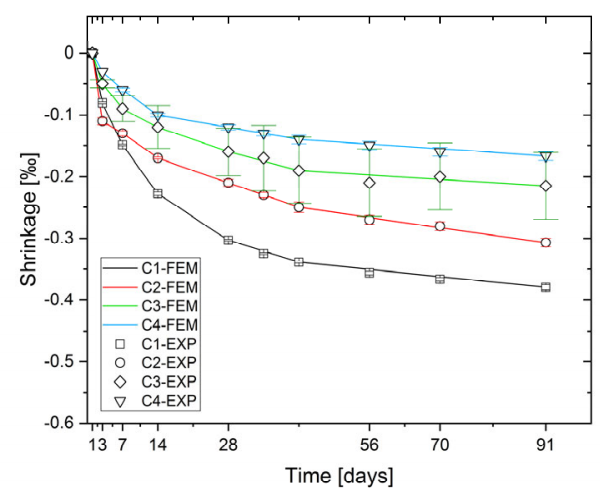

A

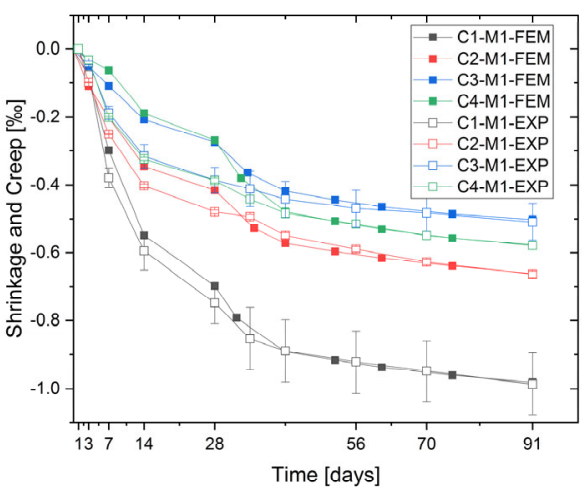

B

Figure 5: Validation of the FEA creep and shrinkage material models. The left graph (A) shows the results of the shrinkage modelling as colored lines in comparison to the experimental shrinkage data. The experimental shrinkage data is shown as symbols including their standard deviations. The right graph (B) shows the results including creep and shrinkage.

The simulation was performed for the two most extreme concrete mixtures ( $\mathrm{C} 1$ and $\mathrm{C} 3$ ) in combination with the two CFRP materials at two tendon prestress levels (800 MPa and $1200 \mathrm{MPa}$ ). The prestress levels were chosen according to recent publications in the field of CFRP prestressed concrete $[45,66]$. To investigate the prestress losses related to different processes, the longitudinal stress within one CFRP prestressing tendon was analyzed once considering both shrinkage and creep, once without creep and once without shrinkage. This allowed assigning specific amounts of prestress loss to the different mechanisms and to analyze their evolution over time, up to until $91 \mathrm{~d}$ after casting. The results of the stress development inside the CFRP tendon are shown exemplarily for the combination C1-UHMK13916 in Figure 6 B. All other combinations showed, at their level of transferred prestress, a comparable behavior. The longitudinal stress distribution inside the concrete prism was visualized over time to show the influence of creep and shrinkage on the specimen's internal stress distribution (Figure $6 \mathrm{~A}$ ). The prestress level inside the CFRP tendons was plotted as a function of time for both CFRP tendon materials in the concrete recipes $\mathrm{C} 1$ and $\mathrm{C} 3$ at the $800 \mathrm{MPa}$ prestress level, see Figure 7. For all combinations, most of the losses were predicted by the FEA to appear within the first five weeks after casting. In the eight weeks thereafter, the increase in prestress loss was reported to be very low for all investigated material combinations. For example, the largest additional loss in the last eight weeks occurred for the UHM-CFRP prestressing tendon in C1 concrete and amounted only to $2.2 \%$.

Not surprisingly, due to their very high longitudinal stiffness of $509 \mathrm{GPa}$, the largest total prestress losses were also found for the UHM-CFRP tendons and reached values of $37 \%$ prestress loss in $\mathrm{C} 1$ and $24 \%$ loss in C3. The lower shrinkage and creep of LCHPCs compared to the reference reflected in lower prestress losses for both tendon materials (e.g. UTS @ $800 \mathrm{MPa}=12 \%$ in C1 and $7 \%$ in C3). Hence, the low shrinkage and creep in the LCHPCs were able to reduce the prestress loss for UTS-CFRP tendons by $35 \%$ and for UHM-CFRP tendons by $42 \%$ respectively. Creep, shrinkage and elastic shortening were found all to contribute noteworthy amounts to the final prestress loss. The contribution of the different mechanisms was subdivided into parts and visualized in Figure 8 . 

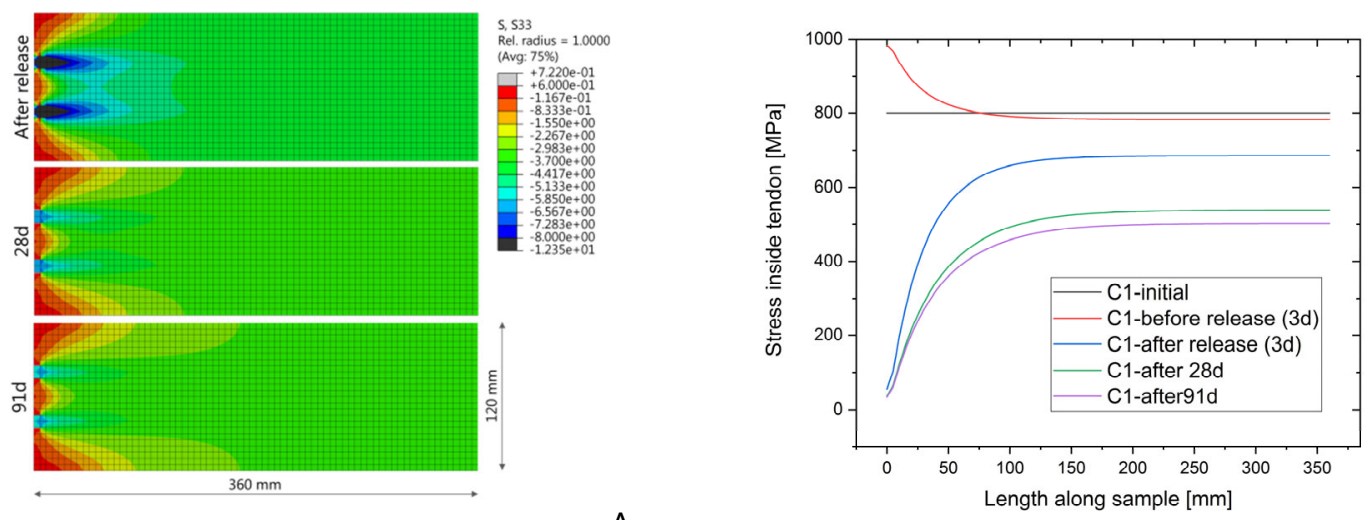

A

Figure 6: FEA results of the prestress transfer behaviour. The left graph (A) shows the longitudinal stress distribution inside the concrete prism for specified time points. After the prestress release, this visualization shows the redistribution of the stresses inside the concrete prism due to concrete creep.

As expected, the stresses in the higher loaded areas of the concrete prism were reduced. The right graph (B) shows the tendon stress along the specimen's longitudinal axis evaluated at critical time points during the FEA analysis, with and without creep and shrinkage. Here, the results are exemplarily

shown for C1 and a UHM-K13916 prestressing tendon. The general behavior of the LCHPCs prestressed with UHM-K13916 CFRP prestressing tendons was comparable. However, differences were present due to the different levels of prestress transfer, concrete creep and concrete shrinkage.

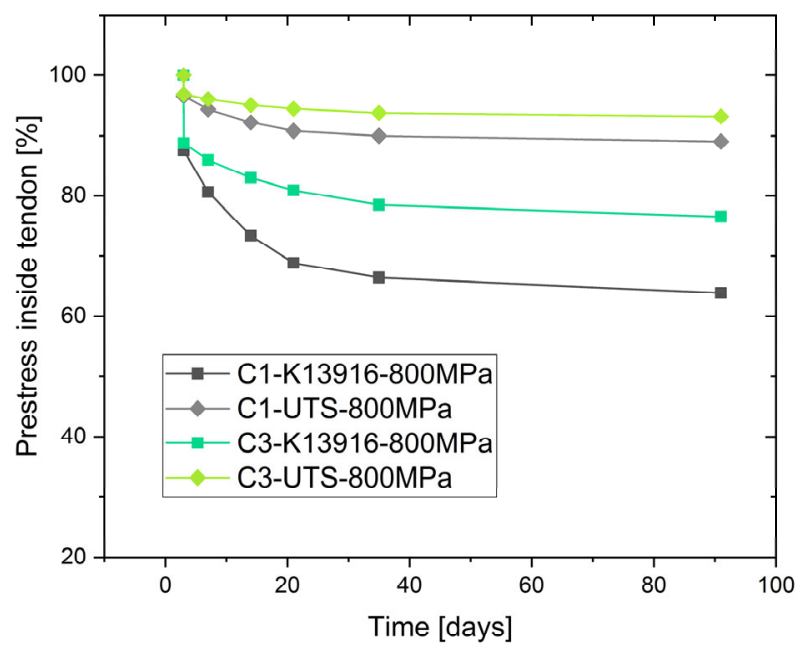

Figure 7: Calculated prestress inside the CFRP tendon from the time point of prestress release until 91 days after casting. In the FEA, the prestress was released 3 days after casting; the value of $100 \%$ prestress corresponds to the prestress inside the CFRP tendon right before the prestress release. Due to shrinkage, this value was already slightly lower than the initial $800 \mathrm{MPa}$. The presented curves include all modelled sources of prestress losses; shrinkage, creep and elastic shortening. The labeling of the lines expresses the chosen concrete in first position, then the CFRP material and the CFRP prestress level, in $\mathrm{MPa}$, in third position. 


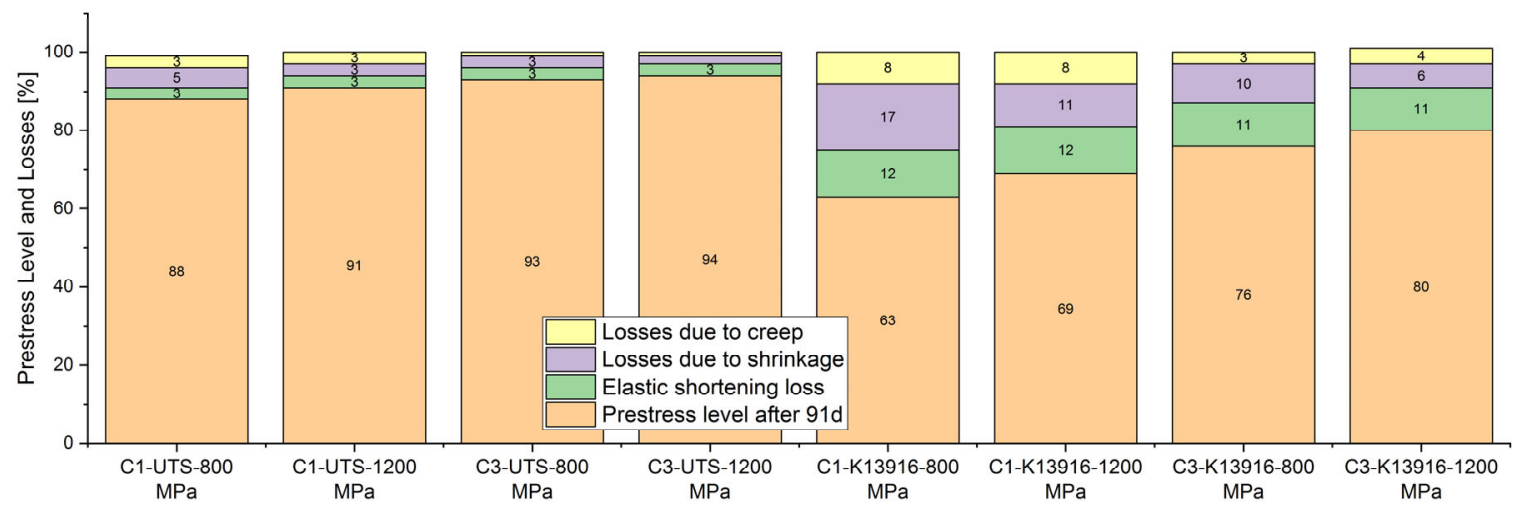

Figure 8: Prestress losses related to shrinkage, creep and elastic shortening after $91 \mathrm{~d}$ based on FEA analysis. The labeling of the columns expresses the chosen concrete in first position, then the CFRP material and the CFRP prestress level, in $\mathrm{MPa}$, in third position.

\section{Conclusions}

Based on the laboratory work during concrete design, the mechanical testing and the modelling of concrete creep and shrinkage in Abaqus 6.14, the following conclusions can be drawn:

- By using limestone and metakaolin as SCMs, it is feasible to design and cast LCHPCs with selfcompacting properties and clinker reduction levels of up to $54-70 \%$. These novel LCHPCs showed very good general mechanical properties, e.g. a high compressive strength between $77-88 \mathrm{MPa}$, and a good bond to sand-coated CFRP tendons. In fact, the bond strength of UHM-CFRP tendons reached 17-21 MPa, not significantly different from the reference concrete $\mathrm{C} 1$ typical for precast prestress applications. Hence, they are considered to be good candidates to be used in CFRP-prestressed structures.

- Prestress losses are significantly dependent on the chosen material combinations. The prestress of a UHM-CFRP prestressing tendon will react very sensitively to small changes in creep and shrinkage, due to the high longitudinal stiffness of these tendons. Low creep and shrinkage of the LCHPC mixtures in combination with a low longitudinal elastic modulus of the CFRP prestressing tendons contribute to a high remaining prestress level in a prestressed structure.

The results of this work show very good potential for improving the current CFRP prestressing technology on structural level. However, these results still focus mainly on the short term behaviour of a prestressed structure. Now, data about the structural behaviour and its integrity over a longer period of time (years) in harsh environmental conditions would be needed. This would bring confidence in industry about this new material trend and finally bring this technology into construction.

\section{Acknowledgements}

This research project is part of the National Research Programme "Energy Turnaround" (NRP 70) of the Swiss National Science Foundation (SNSF). Further information on the National Research Programme can be found at www.nrp70.ch. Mateusz Wyrzykowski was supported by an SNSF Ambizione grant (project 161414, "Role of water redistribution in creep of concrete"). We gratefully acknowledge the financial support of SNSF and Empa. We are grateful to Daniel Käppeli, Marcel Käppeli, and Daniel Völki for their strong support during sample production and testing. 


\section{References}

[1] G. Habert, N. Roussel, Study of two concrete mix-design strategies to reach carbon mitigation objectives, Cem Concr Compos 31(6) (2009) 397-402.

[2] M.C.G. Juenger, F. Winnefeld, J.L. Provis, J.H. Ideker, Advances in alternative cementitious binders, Cement and Concrete Research 41(12) (2011) 1232-1243.

[3] SIA 2052:2016, Ultra-high performance fiber reinforced concrete (UHPFRC) -Materials, design and execution, Schweizerischer Ingenieur und Architektenverein (SIA), Zürich, 2016.

[4] EN 197-1 Cement, Part 1: Composition, Specifications and Conformity Criteria for Common Cements, European Committee for Standarization (CEN), Brussels, 2011.

[5] EN206-1. Concrete-Part 1: Specification, Performance, Production and Conformity, European standard (2000).

[6] R. Wassermann, A. Katz, A. Bentur, Minimum cement content requirements: a must or a myth?, Materials and Structures 42(7) (2009) 973-982.

[7] R. Wasserman, A. Bentur, Effect of concrete composition on durability in natural acidic environment, Advances in cement research 18(4) (2006) 135-143.

[8] N. Buenfeld, E. Okundi, Effect of cement content on transport in concrete, Mag Concr Res 50(4) (1998).

[9] B.L. Damineli, F.M. Kemeid, P.S. Aguiar, V.M. John, Measuring the eco-efficiency of cement use, Cem Concr Compos 32(8) (2010) 555-562.

[10] R. Muigai, M. Alexander, P. Moyo, A novel framework towards the design of more sustainable concrete infrastructure, Materials and Structures 49(4) (2016) 1127.

[11] M. Murat, Hydration reaction and hardening of calcined clays and related minerals. I. Preliminary investigation on metakaolinite, Cement and Concrete Research 13(2) (1983) 259-266.

[12] J. Ambroise, M. Murat, J. Pera, Hydration reaction and hardening of calcined clays and related minerals V. Extension of the research and general conclusions, Cement and Concrete Research 15(2) (1985) 261-268.

[13] J. Ambroise, M. Murat, J. Pera, Hydration reaction and hardening of calcined clays and related minerals. IV. Experimental conditions for strength improvement on metakaolinite minicylinders, Cement and Concrete Research 15(1) (1985) 83-88.

[14] M. Murat, C. Comel, Hydration reaction and hardening of calcined clays and related minerals III. Influence of calcination process of kaolinite on mechanical strengths of hardened metakaolinite, Cement and concrete research 13(5) (1983) 631-637.

[15] M. Murat, Hydration reaction and hardening of calcined clays and related minerals.: II. Influence of mineralogical properties of the raw-kaolinite on the reactivity of metakaolinite, Cement and concrete research 13(4) (1983) 511-518.

[16] R. San Nicolas, M. Cyr, G. Escadeillas, Characteristics and applications of flash metakaolins, Applied Clay Science 83 (2013) 253-262.

[17] M. Antoni, J. Rossen, F. Martirena, K. Scrivener, Cement substitution by a combination of metakaolin and limestone, Cement and Concrete Research 42(12) (2012) 1579-1589.

[18] T. Matschei, B. Lothenbach, F.P. Glasser, The role of calcium carbonate in cement hydration, Cement and Concrete Research 37(4) (2007) 551-558.

[19] P.-C. Aïtcin, High-performance concrete, 1998.

[20] V. Yogendran, B. Langan, M. Haque, M. Ward, Silica fume in high-strength concrete, Materials Journal 84(2) (1987) 124-129.

[21] C.S. Poon, S.C. Kou, L. Lam, Compressive strength, chloride diffusivity and pore structure of high performance metakaolin and silica fume concrete, Constr Build Mater 20(10) (2006) 858-865.

[22] Å. Skarendahl, Ö. Petersson, Report 23: Self-Compacting Concrete-State-of-the-Art Report of Rilem Technical Committee 174-SCC, RILEM publications2000.

[23] B.S.M. Persson, Shrinkage and Creep of High-Performance Self-Compacting Concrete (HPSCC), Autogenous Deformation of Concrete SP-220-11 (2004) 155-180.

[24] H. Okamura, Self-compacting high-performance concrete, Concrete international 19(7) (1997) 5054.

[25] M. Mazloom, A. Ramezanianpour, J. Brooks, Effect of silica fume on mechanical properties of highstrength concrete, Cem Concr Compos 26(4) (2004) 347-357.

[26] D.P. Bentz, O.M. Jensen, A. Coats, F.P. Glasser, Influence of silica fume on diffusivity in cementbased materials: I. Experimental and computer modeling studies on cement pastes, Cement and Concrete research 30(6) (2000) 953-962.

[27] M. Jensen, P.F. Hansen, Autogenous deformation and change of the relative humidity in silica fume-modified cement paste, Materials Journal 93(6) (1996) 539-543. 
[28] T.C. Powers, T.L. Brownyard, Studies of the Physical Properties of Hardened Portland Cement Paste, Bulletin 22, Res. Lab. of Portland Cement Association, Skokie, IL, U.S, 1948.

[29] V. Bonavetti, H. Donza, G. Menéndez, O. Cabrera, E.F. Irassar, Limestone filler cement in low w/c concrete: A rational use of energy, Cement and Concrete Research 33(6) (2003) 865-871.

[30] D.P. Bentz, J. Conway, Computer modeling of the replacement of "coarse" cement particles by inert fillers in low w/c ratio concretes: hydration and strength, Cement and Concrete Research 31(3) (2001) 503-506.

[31] D.P. Bentz, Replacement of "coarse" cement particles by inert fillers in low w/c ratio concretes: II. Experimental validation, Cement and Concrete Research 35(1) (2005) 185-188.

[32] C. Di Bella, M. Wyrzykowski, M. Griffa, P. Termkhajornkit, G. Chanvillard, H. Stang, A. Eberhardt, P. Lura, Application of microstructurally-designed mortars for studying early-age properties: Microstructure and mechanical properties, Cement and Concrete Research 78 (2015) 234-244.

[33] P. Termkhajornkit, R. Barbarulo, G. Chanvillard, Microstructurally-designed cement pastes: A mimic strategy to determine the relationships between microstructure and properties at any hydration degree, Cement and Concrete Research 71 (2015) 66-77.

[34] C. Di Bella, A. Michel, H. Stang, P. Lura, Early age fracture properties of microstructurally-designed mortars, Cem Concr Compos 75 (2017) 62-73.

[35] M. Wyrzykowski, K. Scrivener, P. Lura, Basic creep of cement paste at early age-the role of cement hydration, Cement and Concrete Research 116 (2019) 191-201.

[36] G.P. Terrasi, Mit Kohlenstoffasern vorgespannte Schleuderbetonrohre, ETH Zurich, Zurich, 1998.

[37] G.P. Terrasi, Prefabricated thin-walled structural elements made from high performance concrete prestressed with CFRP wires, Journal of Materials Science Research 2(1) (2013) 1.

[38] P.J. Barr, B.M. Kukay, M.W. Halling, Comparison of Prestress Losses for a Prestress Concrete Bridge Made with High-Performance Concrete, Journal of Bridge Engineering 13(5) (2008) 468-475.

[39] S. Zingg, G. Habert, T. Lämmlein, P. Lura, E. Denarié, A. Hajiesmaeili, Environmental assessment of radical innovation in concrete structures, in: G. Habert, A. Schlueter (Eds.) Sustainable Built Environment (SBE) Regional Conference, Zurich, Switzerland, June 15-17, 2016, vdf Hochschulverlag AG, 2016, p. 687.

[40] A. Leemann, F. Moro, Carbonation of concrete: the role of $\mathrm{CO} 2$ concentration, relative humidity and CO2 buffer capacity, Materials and Structures 50(1) (2017) 30.

[41] A. Leemann, R. Loser, B. Münch, P. Lura, Steady-state O 2 and $\mathrm{CO} 2$ diffusion in carbonated mortars produced with blended cements, Materials and Structures 50(6) (2017) 247.

[42] T. Lämmlein, F. Messina, M. Griffa, G. Terrasi, P. Lura, Bond Performance of Sand Coated UHM CFRP Tendons in High Performance Concrete, Polymers 9(2) (2017) 78.

[43] H.F. Taylor, Modification of the Bogue calculation, Advances in Cement Research 2(6) (1989) 7377.

[44] L. Taerwe, I. Pallemans, Force Transfer of AFRP bars in concrete prisms, Non-Metallic (FRP) Reinforcement for Concrete Structures: proceedings of the Second International RILEM Symposium (FRPRCS-2), Ghent, 1995, pp. 154-163.

[45] G.P. Terrasi, L. Bisby, M. Barbezat, C. Affolter, E. Hugi, Fire Behavior of Thin CFRP Pretensioned High-Strength Concrete Slabs, J Compos Constr 16(4) (2012) 381-394.

[46] G. Terrasi, E. Mclntyre, L. Bisby, T. Lämmlein, P. Lura, Transient Thermal Tensile Behaviour of Novel Pitch-Based Ultra-High Modulus CFRP Tendons, Polymers 8(12) (2016) 446.

[47] EN 12390-3 Testing hardened concrete, Part 3: Compressive strength of test specimens, European Committee for Standarization (CEN), Brussels, 2009.

[48] E. Toumpanaki, J.M. Lees, G.P. Terrasi, Bond Durability of Carbon Fiber-Reinforced Polymer Tendons Embedded in High-Strength Concrete, J Compos Constr 22(5) (2018) 04018032.

[49] E. Sakai, T. Kasuga, T. Sugiyama, K. Asaga, M. Daimon, Influence of superplasticizers on the hydration of cement and the pore structure of hardened cement, Cement and Concrete Research 36(11) (2006) 2049-2053.

[50] G. De Schutter, L. Taerwe, Degree of hydration-based description of mechanical properties of early age concrete, Materials and Structures 29(6) (1996) 335.

[51] A. Boumiz, C. Vernet, F.C. Tenoudji, Mechanical properties of cement pastes and mortars at early ages: Evolution with time and degree of hydration, Advanced cement based materials 3(3-4) (1996) 94106.

[52] M. Vandamme, F.-J. Ulm, Nanogranular origin of concrete creep, Proceedings of the National Academy of Sciences 106(26) (2009) 10552-10557.

[53] C.A. Jones, Z.C. Grasley, Short-term creep of cement paste during nanoindentation, Cem Concr Compos 33(1) (2011) 12-18. 
[54] Z. Hu, J. Ston, M. Wyrzykowski, P. Lura, K. Scrivener, Intrinsic viscoelasticity of C-S-H assessed from basic creep of cement pastes, Cement and Concrete Research (submitted) (2018).

[55] C. Di Bella, M. Wyrzykowski, P. Lura, Evaluation of the ultimate drying shrinkage of cement-based mortars with poroelastic models, Materials and Structures 50(1) (2017) 52.

[56] M. Wyrzykowski, P. Lura, F. Pesavento, D. Gawin, Modeling of internal curing in maturing mortar, Cement and Concrete Research 41(12) (2011) 1349-1356.

[57] Z.C. Grasley, C.K. Leung, Desiccation shrinkage of cementitious materials as an aging, poroviscoelastic response, Cement and Concrete Research 41(1) (2011) 77-89.

[58] P. Lura, O.M. Jensen, K. van Breugel, Autogenous shrinkage in high-performance cement paste: An evaluation of basic mechanisms, Cement and concrete research 33(2) (2003) 223-232.

[59] M. Wyrzykowski, P. Lura, Effect of relative humidity decrease due to self-desiccation on the hydration kinetics of cement, Cement and Concrete Research 85 (2016) 75-81.

[60] B.t. Bissonnette, P. Pierre, M. Pigeon, Influence of key parameters on drying shrinkage of cementitious materials, Cement and Concrete Research 29(10) (1999) 1655-1662.

[61] F. Meftah, J. Torrenti, W. Nechnech, C. de Sa, An elasto-plastic damage approach for the modelling of concrete submitted to the mechanical induced effects of drying, (2000).

[62] P. Gerald, The Effect of Change in Moisture-Content on the Crepe of Concrete Under a Sustained Load, Journal Proceedings 38 (1942) 333-356.

[63] ACl 440.4R-04, Prestressing concrete structures with FRP tendons, (2004).

[64] A.O. Abdelatif, J.S. Owen, M.F.M. Hussein, Modelling the prestress transfer in pre-tensioned concrete elements, Finite Elements in Analysis and Design 94(0) (2015) 47-63.

[65] Abaqus Analysis User's Manual 6.12, 22.7.1, Dassault Systèmes2012.

[66] G. P. Terrasi, U. Meier, Long term bending creep behaviour of thin walled CFRP pretensioned high strength spun concrete poles under sustained load, CICE 2014, The 7th International Conference on FRP Composites in Civil Engineering, International Institute for FRP in Construction, Vancouver, 2014. 